\title{
THE ARCHAEOLOGICAL PARK OF NAVELLI (ITALY) IN THE RECONSTRUCTION PLAN: HYPOTHESIS OF ADAPTIVE REUSE
}

\author{
I. Trizio ${ }^{1,}$ *, M. De Vita ${ }^{1}$, A. Ruggieri ${ }^{2}$, A. Giannangeli ${ }^{1}$ \\ ${ }^{1}$ ITC-CNR, Institute for Construction Technologies, Italian National Research Council, \\ 67100 L'Aquila, Italy - (ilaria.trizio, DeVita, Giannangeli)@itc.cnr.it \\ ${ }^{2}$ Department of Biosciences and Territory, University of Molise, 86100 Campobasso, Italy - a.ruggieri3@ studenti.unimol.it
}

\author{
Commission II - WG II/8
}

KEY WORDS: Architectural Heritage, Post-earthquake reconstruction, Adaptive Systems, Urban Regeneration

\begin{abstract}
:
This study is aimed at identifying adaptive design strategies applied to the particular contexts of the Abruzzo Region during the postearthquake reconstruction. The area affected by the calamitous event present material and immaterial issues to be interpreted and managed according to integrated and interdisciplinary intervention methods. In this context, the Reconstruction Plans (PdR) provide the guidelines for a coherent territorial development, proposing design solutions that call for sustainability and resilience. The village of Navelli, which 10 years after the earthquake is still in a serious state of damage and abandonment, is identified in the 2013 PdR as an area to be converted into an archaeological park. The Plan prescribes by specifications on the basis of identifying values of the area whilst inspections carried out reveal a stratified, vast and remarkably heterogeneous building fabric both as regards to the level of damage and the values to be protected. From the analyzes carried out, the case study provides the opportunity for an ad hoc design methodology, identified by specific interventions that are at the same time inter-dependent and included in a complex project. The work highlights how the overall design of a public space can find an easier resolution in the integration of adaptive and reversible technologies, coherent with the sustainable development suggested by the PdR.
\end{abstract}

\section{INTRODUCTION}

\subsection{Foreword}

The seismic crisis that hit the territory of L'Aquila in 2009, followed by that of central Italy in 2016, has once again highlighted the theme of minor historical centers. In particular, we refer to the area of the internal Apennines, dramatically observing the decline of these centers over a long time due to the inexorable processes of abandonment and advanced degradation (Andreassi, 2019). In fact, in the last century the collapse of the agro-pastoral economy, upon which these centers were mainly dependent, has determined a strong demographic decline and, consequently, a general abandoning of places in spite of their recognized cultural and environmental values (Ciccozzi, Cerasoli, 2018).

The future of this built heritage, unless the hypothesis of deliberately and definitively leaving these realities is taken seriously (Andreassi 2016), is largely linked to the choices and strategies that the reconstruction of these territories will be able to implement. Despite the obvious critical issues, the possibility that these centers find in themselves the potential to regenerate, starting from the use of the cultural and material inherited from the past, is already slowly beginning to make its way. Some recent examples of historic centers of the Abruzzo seismic crater, such as Fontecchio, testify that there is actually the possibility of stimulating countertendencies (Ciccozzi, Cerasoli, 2018) capable of changing the minor centers paradigm, endangered in the fragile areas of our territory, through forms of the participation of local communities and self-governance of goods (De Bonis, Giovagnoli, 2019).
One of the decisive factors for those who want a true revitalization of these realities is precisely the central role that Cultural Heritage in general and in particular the built landscape play in the conservation of territorial identities, the rebirth of places (Volpe, 2019) and, above all, of communities, in absolute respect of the Faro Convention (Faro Convention, 2005).

\subsection{The Reconstruction Plans}

The Reconstruction Plans (PdR) represent the chosen tool, according to the law $n$. 77 of 2009 , to guide the reconstruction of the 56 historical centers of the municipalities of the seismic crater of L'Aquila. Three years after the law that decreed its use, the subsequent law n. 134 of 2012 declared the end of the state of emergency by setting a time period of 120 days for the preparation of the PdR, giving this tool a strategic nature and, optionally, an urban planning nature. The strategic nature of these Plans aimed at quantifying costs and the time necessary for reconstruction and regulating the methods for implementing the reconstruction activities; the urban nature on the other hand concerned plans whose contents had to modify, integrate or replace the existing urban tools (USRC, 2017). The primary intent of the PdR was therefore to deal with the interventions on the damaged stock of building heritage in the absence of adequate urban planning tools and to preserve the historic centers with their architectural values and, also, trying to revive them through compatible uses so as to carry out a socio-economic revitalization of the territory (Andreassi, 2016).

At present, 55 of 56 municipalities have prepared their PdR and have reached the end of the formal procedure, only one has had to follow a specific procedure since it has not reached the end of the path within the legal time limits.

\footnotetext{
* Corresponding author
} 
Among these 55 municipalities, only 8 have drafted a PdR of strategic nature, while the remaining 47 have prepared a PdR of urban nature (data source: USRC). Among the main purposes of the PdR, the "historical center" of each municipality represents an ensemble of landscape, history and artistic value to be protected as a whole, a "unicum". Despite this assumption and although the PdR recognizes that reconstruction is a complex phenomenon, which integrates in a single instrument the different relationships between: the economic dimension; socio-economical recovery; urban planning; the redevelopment of the town; the social one, with the return of the populations - (STM, 2010), the risk is that with the time needed between the drafting and the application of the Plans, together with the fact of not having sufficiently reflected on the real demand for the use of the places, leads to a new phase of decline of these assets (Andreassi, 2016).

\subsection{Case study: Navelli village}

In this paper, we have tried to critically analyze the ways in which the specific (landscape, typological, formal) characteristics of a minor historical center, in this case Navelli village (Figure 1), have deteriorated through the Reconstruction Plan. Navelli is a village about $35 \mathrm{~km}$ from L'Aquila, which dominates the area of the same name. It is located on the south-west side of Monte San Nicola, close to the state highway that connects the regional capital of Abruzzo to Pescara. The area was already inhabited in the times of the Vestin tribe and the name of the first settlement was Incerulae. After the fall of Amiternum, in the third century B.C., and the consequent Roman conquest of the territory, Incerulae was governed by the Prefecture of nearby Peltuinum and the area will have benefited from the opening of the Via Claudia Nova, which crossed the Navelli uplands, and from the proximity of the Tratturo Magno, an important communication route for carrying out pastoral activities.
Following the fall of the Roman Empire, even in these territories, peoples began to occupy sites at high altitudes, then to return to the small settlements spread in the plain and, following the Lombard conquest and the spread of monastic communities and Christianity in the area, to the practice of farming (AA.VV., 2002).

But it is only in the Middle Ages, with the building of castles and fortifications in Abruzzo (Redi, 1997; Forgione, 2018) and populations returning to the plateaus, that Navelli was founded on its current site and for the first time the castle of Navelli was mentioned in a seal of the nearby Monastery of San Benedetto in Perillis (Giammarco et al., 1984). Nine "Villas" participated in the foundation of the fortified village, that is nine communities from the inland territory who decided to gather in a single settlement capable of responding to the needs of defense, communication, exposure and sustenance (AA.VV., 2002; AA.VV., 2005).

The original Navelli was surrounded by walls whose morphology had been conditioned by the orography of the site, as well as the choice of the building typology made of terraced houses in limestone arranged in parallel to the contour lines and separated by a narrow service road.

The inhabited center was heavily damaged by the earthquake of 1456 and, following its reconstruction, the original layout of the village was enlarged and a new wall layout, characterized with three doors, was built. With this expansion, which was determined by a demographic increase due to a migratory flow from neighboring inhabited centers which had been completely destroyed by the seismic event, two other different types of construction were introduced: the terraced house with an orthogonal trend to the contour lines and the arched houses.

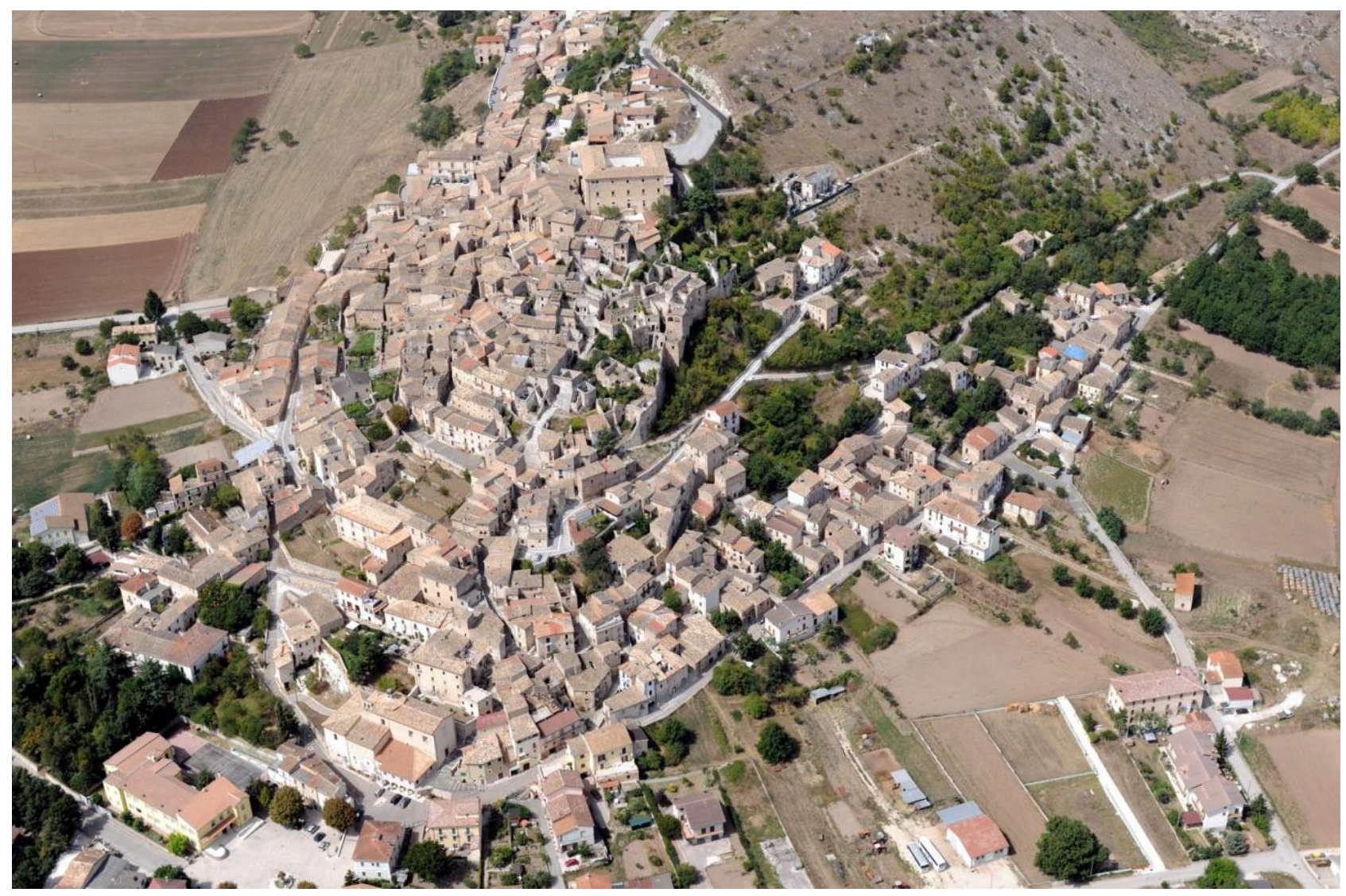

Figure 1. Aerial view of Navelli (photo: Report of the RdP, p. 33). 


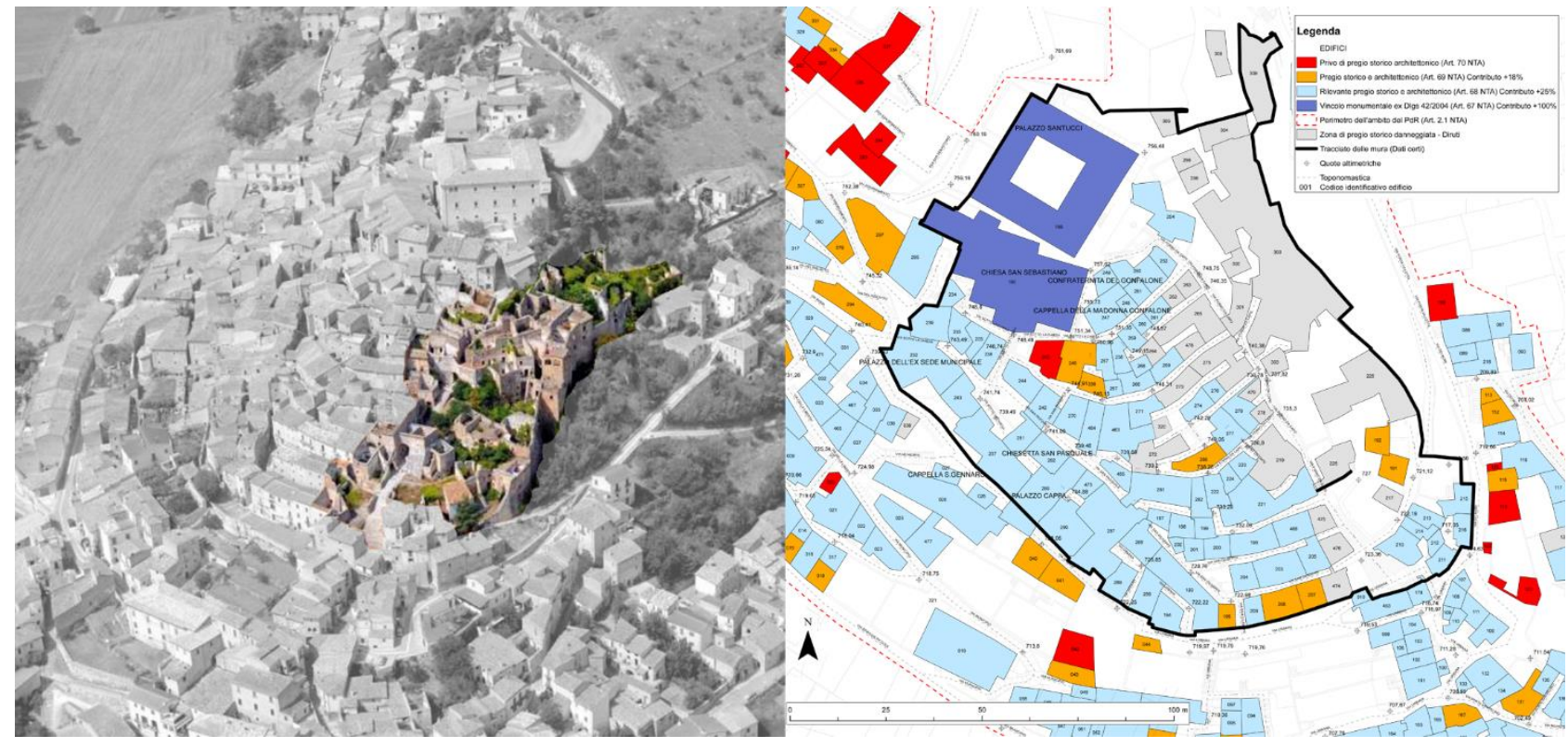

Figure 2. On the left: aerial view of Navelli with the case study zone highlighted; on the right: RdP chart focused on the area inside the ancient walls.

The only palatial building dates to this period, with the construction of Palazzo Santucci at the highest point of the settlement (AA. VV., 2006). This general system remained intact until the earthquake of 1703 , which significantly damaged all the inhabited centers of the plateau, including Navelli itself. The earthquake led, once again during the reconstruction phase, to introduce a new building type of the city wall, fully supported by the old walls, which, due to the changed political balance, had definitively lost their defensive role (AA. VV., 2005). With the new reconstruction of the village, the impact of migration, to and from the village of Navelli, the town expanded towards the valley, outside the walls, which changed its use, together with the extension to a palatial building inside the walls, favored by the influx of workers from other areas of Italy (AA.VV., 2005). Due to the crisis of the pastoral system, at the end of the nineteenth century, the first migrations lead to the abandoning of a large part of the historic center, a phenomenon that will be accentuated by the massive emigration that characterized these lands in the forties of the last century, at the end of the Second World War (AA.VV., 2005).

\section{A RECONSTRUCTION PLAN FOR NAVELLI: VALUES TO PRESERVE}

\subsection{Architectural values of the building system}

The village of Navelli, like other fortified historic centers in the same geographical area, was planned to achieve a balance between the physical characteristics of the site, the defensive needs of the inhabitants and those related to sustenance. In this sense, the choice of the site is indicative, halfway up a hill overlooking the plain, to be able to satisfy all the requirements simultaneously, including the exploitation of the plateau's land. Since the morphology of the village is linked to the reconciliation of various needs, the building fabric of Navelli reflects the housing needs that have evolved over time, the changes that have occurred due to the succession of earthquakes and the economic vicissitudes of the territory. Terraced housing is the original typology of the village, based on a unit of about $4.5 \times 4.5$ meters consisting of one or two overlapping rooms, generally with only one view, of which the lower one was dedicated to productive activities, trade or livestock and the higher one to the home (Zordan et al., 2002).
The two levels are connected with an internal staircase if the building was dedicated entirely to the housing function, while an external staircase connected the two floors in case of different uses. Following the reconstruction in 1456 the village assumes a different and more compact structure thanks to arched housing, a new type of building characterized by adding a room to a row. Arched housing improves the buildings performance from a static point of view and allows terraced houses to expand responding to housing needs to increase square footage (AA.VV., 2005).

The reconstruction following the earthquake of 1703 permits walled houses to be introduced in the style of the village buildings. Walled houses together with terraced housing constitute the supporting framework of the building system, to which the arched housing type ensures stability (AA.VV., 2005). From a constructive point of view, the walls of local limestone is the constant that evolves together with the village itself, trying to better adapt to the growing housing needs and to improve over time also the seismic reaction of the structures and the performance necessary due to the additional loads. Although the evolution of the wall type in the various phases is legible, the final result is still homogeneous, even in the buildings built following the reconstruction of 1703 and resulting by the fusion of different terraced houses.

From this rapid analysis it emerges that, in all of the historic center, the main character to be safeguarded is the masonry of the entire village. The masonry, even if enriched by profferli, cantonal, doors and window frames and raised arches remains the same despite its evolution.

Precisely the wall system, in its entirety is: "the basic element that extends to the urban system according to construction rules so that the structure of the ancient village can be compared to a single macro-building" (Zordan et al., 2002, p. 57) and the construction system undergoes: "a sort of evolution of the construction closely linked to the modification of the static and mechanical behavior of the box-like plant, according to the morphological changes done on the plant itself" (Zordan et al., 2002, p. 58). 
2.2 The regeneration of the village towards an archaeological park and urban gardens

The case study refers to an area of Navelli which was expanded following the earthquake of 1456 (Figure 2), and which develops to the right of the stairway of Via Forno da Capo, built on the steepest slope of the built-up area. The buildings, mainly two and three levelled terraced houses orthogonal to the contour lines and to the wall houses, are in a state of disrepair since the end of the nineteenth century when, according to the sources, a structural intervention was already desired. Obviously, with the depopulation due to the Second World War highlighted in Abruzzo, the degradation became even more evident.

The area is characterized by a series of buildings in serious state of disrepair (Figure 3), to the extent that it was object of a Building Heritage Recovery Plan in 2002 and, in the same year, of a plan for the Recovery of the Historic Center (AA.VV., 2005).

The Navelli Reconstruction Plan, drawn up in 2013 by the DICATeA Department of the University of Parma (PdR, 2013), in defining the criteria and methods of intervention, addresses the problems related to this area starting with the fact that the 2009 earthquake only worsened a situation of previous damage, which makes reconstruction and a return to previous use unlikely.

Despite this, the position and attractiveness of the area present a valuable urban landscape value to be protected and valorized. (PdR, 2013). Therefore the Plan, taking into account the problems related to the private ownership of many of the buildings in the area, aims at a recovery of the more degraded properties assuming, after the consolidation of the surviving walls, the creation of an archaeological park with green arrangement of the internal areas, thus creating a sort of terraced garden with panoramic views of remarkable landscape value (PdR, 2013).

It is clear that as the Plan foresees an archaeological park and in view of the value of the landscape of the entire area it would also be desirable to study the creation of green areas within the original cells in order to highlight the typology of what remains of the inhabited area and to facilitate an integrated approach to its entirety, starting from the surviving masonry portions.

\section{A REGENERATION PROPOSAL THROUGH ADAPTIVE REUSE STRATEGIES}

\subsection{Adaptive solutions for the recovery of Cultural Heritage}

Adaptive re-use is defined as "any building work and intervention aimed at changing the capacity, function or performance to adjust, re-use or upgrade a building to suit new conditions or requirements" (Gustafsson 2019; Douglas, 2006).

While reuse refers to the renewal of the use of a disused structure, the "adaptive" term suggests the possibility of updating the functions and uses of a building, regardless of the state of conservation at the time of the intervention.

Therefore, adaptive reuse refers to the possibility of dedicating to a certain space changes over time depending on external variables that can occur and affect the use of the building itself and consequently on its management / maintenance, and ultimately on its life cycle. From this it is evident that adaptive reuse is strictly connected to issues of resilience, temporariness and, not least, to environmental sustainability and materials performance. Designing an adaptive reuse is therefore a theoretical and cultural question, as much as practical, economical, environmental, formal and, above all, technological issues.

A prerequisite for adaptive reuse is the use of architectural technology. Actually, the wise choice of materials and construction systems to use will inevitably condition the compliance with the requirements of flexibility, reversibility, recycling and dynamism.

Imagining the re-design of places and landscapes through technologically effective and architecturally innovative solutions becomes the driver of a regeneration which starting from the physical extends to the urban and social scale. It has also been estimated that the greater the values of the heritage with which the community associates, the more virtuous and effective methods of use are triggered following the intervention, expressing values independent of the use itself (Cerreta, Panaro, 2017; Porter, Kramer, 2011). Aiming at the effectiveness of an adaptive reuse intervention is very complex, especially considering that the related project does not allow designers to take rely on predictions based on previous experiences.
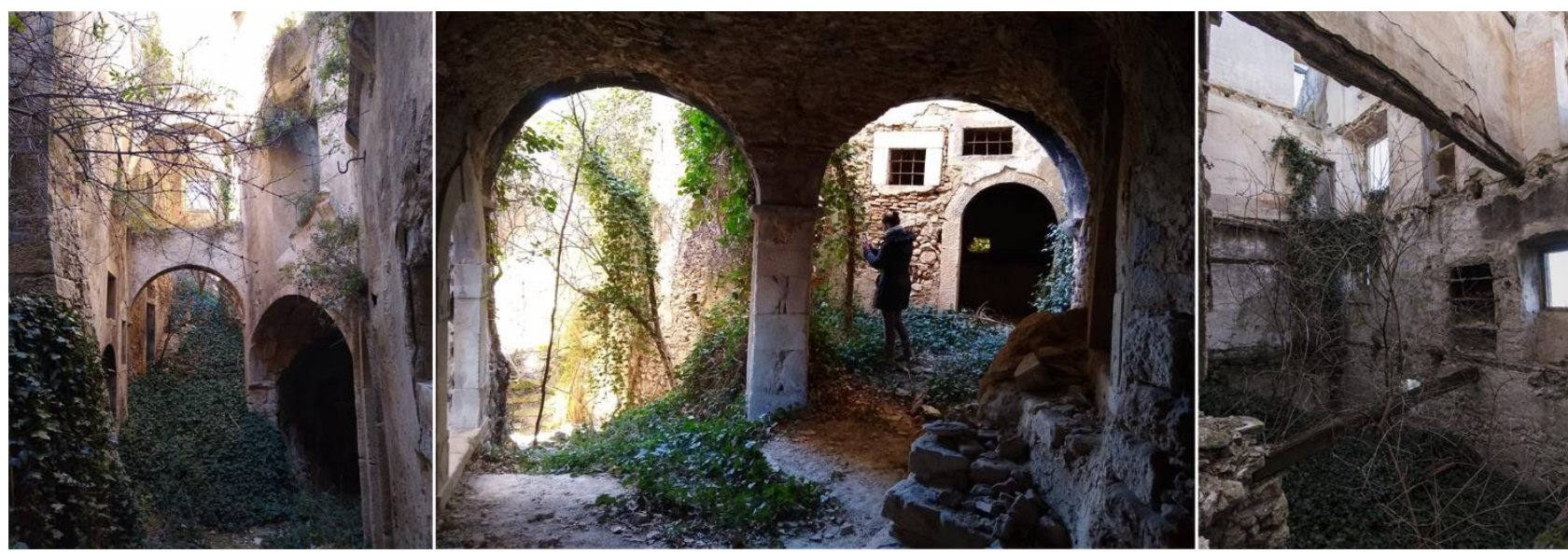

Figure 3. Views from the on-site visit to the case study location. 
Firstly, in order to limit the risks, the multidisciplinary and multidimensional aspects of the design must be carefully calibrated. These aspects must be referred primarily to a bottomup approach to design, rather than top-down, since the usercitizen is the first beneficiary of the reuse process, whose requirements must be taken into full account.

Adaptive urban reuse must in fact be understood as an instrument aimed at connecting spaces, whether they are large urban voids or interstitial spaces, both in the less densified suburbs and among the more consolidated urban areas, with the aim of integrating nodal points and ensure synergy between them.

Since not only homes, but also today's cities present complex problems which are in rapid evolution, resilient urban systems are necessary, capable of absorbing these issues and providing equally fast responses to change being interactive, adaptive, reversible, flexible, light and with low impact. These systems must be able to change according to inputs coming from the constant exchange with the environment. Through micro-strategies of sustainable reuse of urban heritage it is possible to activate projects capable of contemplating spatial transformation in a flexible and possibly temporary form, always with a focus on sustainability.

These micro-strategies also mean micro-design, which becomes a useful tool, for example to solve the configuration of interstitial spaces between buildings and open places within urban fabrics, permitting their redesign in terms of an integrated system of interconnected elements.

A valid principle to be respected as a reference model for the realization of adaptive reuse interventions is that of the circular economy, which is based on the sharing and re-cycling of resources, raw materials and strategies to reduce waste, which in our case can result in the enhancement of the existing heritage rather than on the consumption of resources and soil for new constructions. In this framework, historical heritage represents the economic, as well as cultural, capital in which to invest.

The EU H2020 1 CLIC project was born from these ideas and aims to attract new sustainable investments from an economic and financial point of view for the recovery of abandoned buildings and landscapes of cultural value. Through reuse, historical buildings and ruins are given new life and thanks to appropriate governance models, processes of social capital renewal and cultural capital enhancement is triggered, which must be interpreted in a flexible manner and not as shapes fixed in time and space. (Daldanise et al., 2019).
According to Renzo Carlucci (Carlucci, 2019), a smart restoration and adaptive reuse of unused or badly used historical buildings can bring remarkable economic results and social development for cities and territories, while reducing urban sprawl.

Due to its remarkable potential, the theme of adaptive reuse has been one of the main focuses of the European Year of Cultural Heritage: the Leeuwarden declaration entitled Adaptive re-use of the built heritage: Preserving and enhancing the values of our built heritage for future generations was produced on this occasion. The attention towards adaptive reuse by the European Community, and the consequent cultural impact on the international scientific community found in various active research on this topic, allow designers to approach the theme with the certainty of finding a framework in a system that has already declared its fixed points and established its rules.

However, the design practice is hampered by both bureaucratic difficulties and the reconciliation of traditional best practices with innovative approaches to the historical building, which has always been the preserve of restorers. Therefore, technological solutions that can translate the theories discussed by research and politics into architecture need to be found: nowadays this step is necessary in order to make the adaptive reuse of Cultural Heritage concrete and possible.

\subsection{Proposals for the enhancement of the village}

The area under study is identified in the reconstruction plan as "a place of particular quality and landscape value" (PdR, 2013). The vocation for interventions that have resonances and consonances at urban level is therefore proof that the future redevelopment of the area will have to considered.

Furthermore, on the basis of the inspections carried out, it is not advisable to plan future enhancement projects on the basis of single building interventions. In fact, this would lead to the fragmentation of a highly characterized urban fabric, identifiable in a constructive, typological and functional continuum that cannot be dissected. The connotation of the site as an interconnection space between different village areas is instead emphasized by the presence of a large stairway that crosses the entire north-east belt of the village (Figure 4), precisely defining the boundaries of the second urbanization of the village, dating back to the XV- XVII. The stairway, as a main artery for the distribution of flows, introduces the unfolding of environments that seem to decline the connotation of closed and open space according to different architectural possibilities.
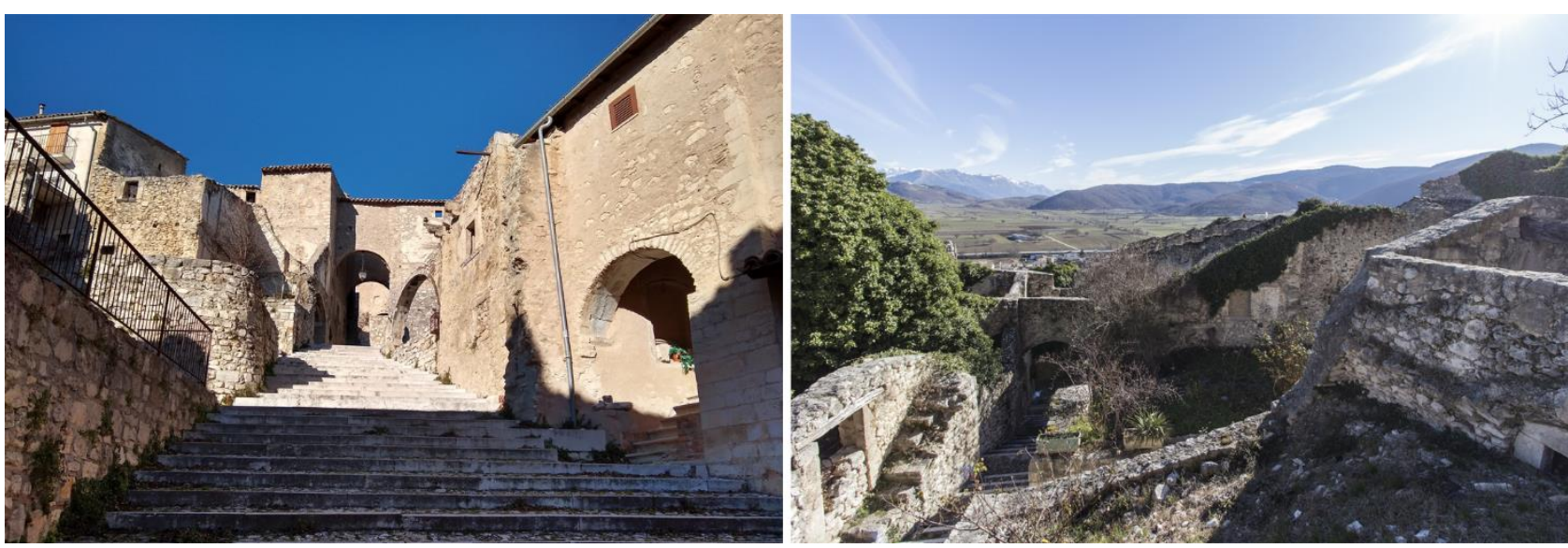

Figure 4. On the left: view of the main stairway; on the right: view of the site from the top of the stairway. 
The area of intervention, already in a state of decay, demonstrates the qualities of a hybrid space, on the border of public and private locations, between large openings and areas with a high building density.

At present, the structures are deeply lacerated, structurally with very serious damage due to the partial or total collapse of many floors and, in some cases, of entire buildings. On the other hand, it can be said that the serious damage following the 2009 earthquake provides more scope for future planning, reducing its constraints. In this sense, the intervention can be designed to be characterized by more innovative solutions both from a technological and aesthetical point of view, especially compared to those most commonly used in heritage restoration.

The suggestion made in the Reconstruction Plan to dedicate the area to an Archaeological Park undoubtedly creates a vocation of the place to be the bearer of an urban, even territorial, enhancement. The interventions proposed in the Plan therefore provide for a partial reconstruction of the buildings, taking into account the ruin state of many of the collapsed structures and finally ensuring greater permeability of the urban fabric to the public and the usability of the places in total safety.

Without prejudice to the redevelopment requirements prescribed by the Plan, the design possibilities from a technological and architectural point of view are numerous. In fact, the area appears to be suitable for hosting solutions which, while respecting the compatibility and protection of the values expressed by historical architecture and landscape, are at the forefront and offer themselves as drivers for the enhancement of the whole village.

In summary, the urban renewal must be oriented towards: enhancing the Cultural Heritage; non-invasiveness of the interventions; compatibility with architectural and landscape heritage; guaranteeing non-interference between public and private spaces; enhancing the usability of open and hybrid spaces; recovering and restoring the buildings to rebuild; and securing the buildings to be used as ruins.

In order to promote the enhancement of the village by exploiting innovative technological solutions, the intervention must be guided by further sustainability criteria, reconciling them with the needs expressed by the Plan. These criteria are: the resilience of places and architecture; the reversibility and flexibility of the technological solutions adopted; the non-invasiveness and low impact of plants and installations; environmental, energy and economic sustainability of the interventions.
The intersection of these criteria suggests the approach of adaptive reuse, understood as the possibility of intervening on the Cultural Heritage, built or not, according to an optimization of materials and resources, triggering virtuous mechanisms of environmental and cultural enhancement.

Concerning technology, the systems capable of adequately responding to the project requirements are certainly dryprefabricated systems, whose lightness and flexibility must be guaranteed by reversible assembly methods and with joints that allow movements that make the structures potentially convertible.

Among the various construction possibilities, that of the textile adaptive wrapping can provide a concrete contribution in responding to the requirements for adaptability and flexibility posed by adaptive reuse. Starting from the experiences of F. Otto and B. Fuller, textile transformable covers have been designed since the 1950s to cover or discover spaces whenever the need arises and in a completely reversible way.

Traditionally, convertible roofing systems in warm and Mediterranean areas are mostly used as shading systems, while in the North their use is mainly seasonal in order to have covered and closed places in winter and open air in summer. In recent years, a further need is emerging which is to have covers that can be opened quickly and easily, above all to ensure the continuation of sporting events, shows and exhibitions as weather conditions change.

The design of roofs and enclosures with these characteristics is today a very niche sector, for few experts. In Europe, the universities that deal with them through their research groups are those of Nottingham, the Flemish University of Brussels, those of Stuttgart, Seville, and the Politecnico of Milan.

Here we hypothesize the design of some of these typical structures, inserting them into two of the numerous open places to be re-designed in order to host new attractive and compatible events in the new archeological park.

Figure 5 shows the hypothesis of membrane umbrellas that can be easily installed, removed and kept open or closed depending on the users needs.

Figure 6 shows the design of a membrane solution for the covering of a small garden. The two solutions represent a possibility offered by the installation of typical textile enclosures, but they are not exhaustive.
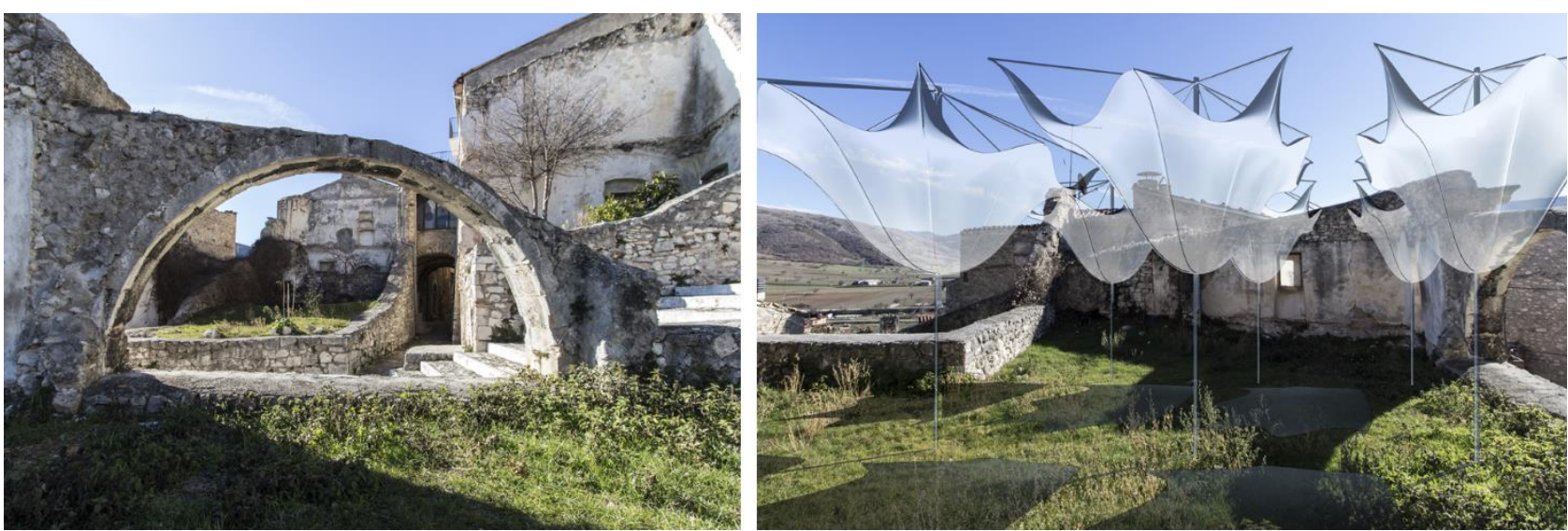

Figure 5. Re-designing an open space through adaptive umbrella covering system. 


\section{CONCLUSIONS}

The redevelopment of Cultural Heritage is a very complex issue, which involves diversified professional roles and which concerns both the technical aspects - structural safety, plant adaptation, protection of historical-artistic values - as well as those theoretical of a social and cultural impact.

All these aspects must be related and balanced in the framework of a constant dialogue, in order to never be separated from each other in a coherent process of redesigning cities, territories and landscapes.

Within this vast area of "capital-heritage", in this work we study the case of historical buildings in states of serious damage and/or abandonment. These represent a real economic capital to be exploited through valorization which will trigger reactions of cultural, social, economic and urban requalification. The state of serious damage often opens up new possibilities for intervention that find adaptive reuse as a sustainable solution from both an environmental and financial point of view, aiming to ensure adequate resilience to locations.

The village of Navelli, seriously damaged by the 2009 earthquake that hit the Abruzzo Region, is an ideal case study for the application of adaptive reuse criteria. This work is a first study of the possibilities of intervention to be applied on the occasion of the redevelopment of the north-east area of the village, deserted since the 1800s and which, due to the recent earthquake, shows serious structural damage.

This paper makes hypotheses of adaptive reuse applicable to the village of Navelli and consistent with the redevelopment of the area to be used as an archaeological park, as proposed by the Reconstruction Plan.

The hypotheses of advanced intervention concerns the installation of transformable envelopes and textile covers through the use of totally reversible light systems, capable of modifying the use of the area over time, thus adapting to variable conditions of use.
Textile architectures are, among the transformable envelopes, the ones that have lent themselves most to new experiments and uses.

The technologies offered by textiles can be summarized as follows:

- Membrane structures that can be divided into fixed (i.e. cable network or cobwebs systems - in tree or wheel configuration) or mobile (i.e. folding toldos, extensible systems, tensegrity, umbrellas and up/down covering) according to the structure typology;

- Shell structures that can be divided into folding, telescopic, diaphragm and pivoting systems.

Among the various possibilities, the use of membranes is suitable for umbrella structures with an up/down opening mechanism, while for telescopic, diaphragm and pivoting structures, shells are the most desirable solution.

Transformable textile covering are attributable to a sort of "high tech" temporariness, able to optimize the performance of light enclosures compensating the environmental criticalities presented by these low thermal inertia structures with flexibility and adaptability to different conditions of use. These systems, integrated into the historical buildings without being invasive, can coexist with the restoration aims, defining open, hybrid or even closed spaces and characterizing themselves with formal, material and structural lightness.

\section{NOTE}

Although this contribution was prepared jointly by the authors, paragraphs 1 and 2 are to be attributed to Ilaria Trizio, while paragraphs 3 and 4 to Mariangela De Vita.

Furthermore, Alessandro Giannangeli elaborated the photogrammetric survey of some portions of the case study and Andrea Ruggieri the 3D model and the render of the project proposal.
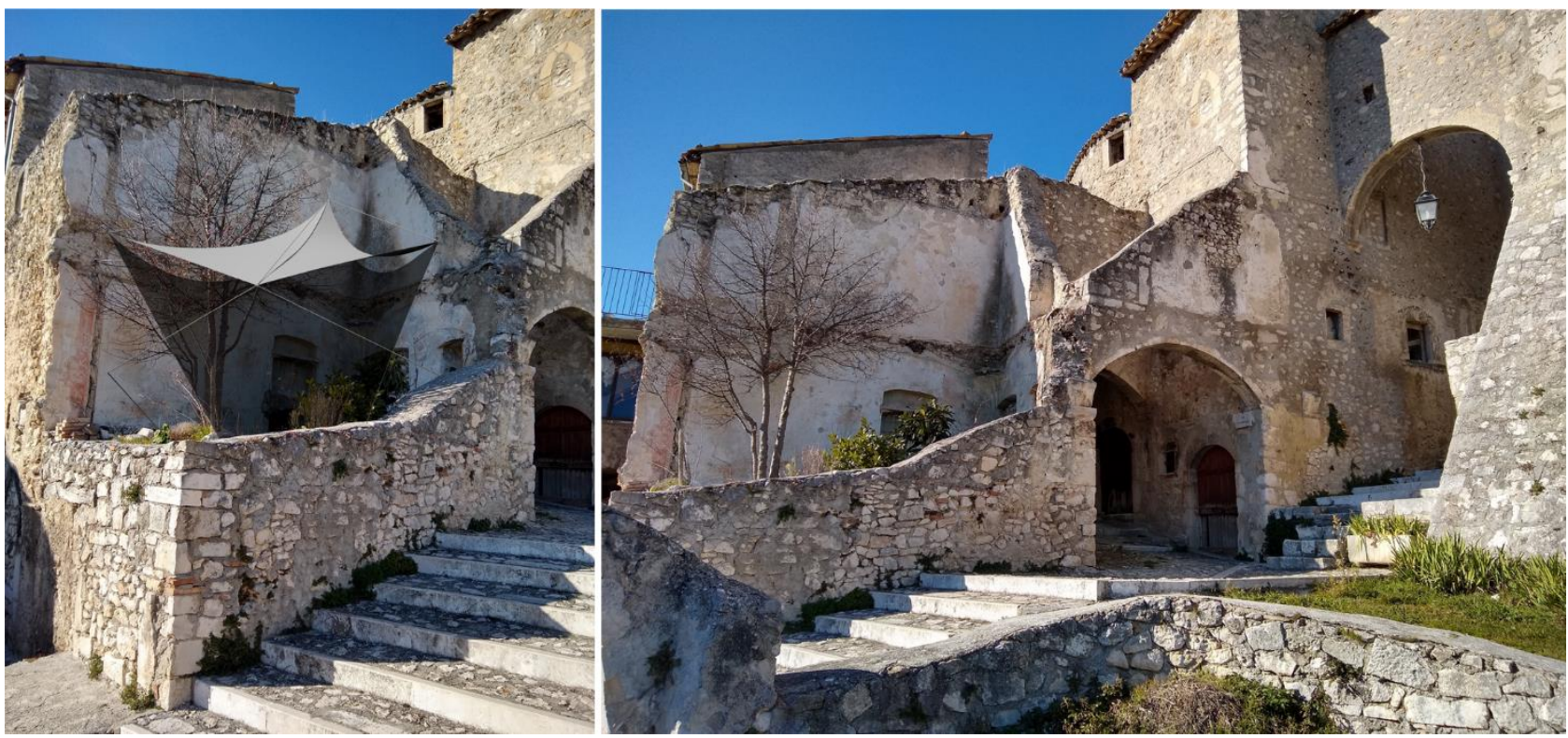

Figure 6. Imagining temporary shadows on a little garden. 


\section{REFERENCES}

AA. VV., 2002. Il settecento a Navelli. Casa editrice Tinari, Villamagna $(\mathrm{CH})$, Italy.

AA.VV., 2005. Il novecento a Navelli. Casa editrice Tinari, Villamagna $(\mathrm{CH})$, Italy.

Andreassi, F., 2019. L'Aquila. Riscritture urbanistiche. Aracne, Canterano (RM).

Andreassi, F., 2016. Urbanistica e decrescita. Tra restringimenti, abbandoni e ricostruzione. Il ruolo dei centri storici minori. Aracne, Ariccia (RM).

Bonamico, S., Tamburini, G., eds., 1996. Centri antichi minori d'Abruzzo. Gangemi, Roma.

Carlucci, R., 2019. Orientamenti europei per sostenere il riutilizzo adattivo degli edifici storici nel 2019-2020, Archeomatica, Tecnologie per i beni culturali. https://www.archeomatica.it/editoriali/orientamenti-europei-persostenere-il-riutilizzo-adattivo-degli-edifici-storici-nel-20192020 (last visit 14/01/2020).

Cerreta, M., Panaro, S., 2017. From perceived values to shared values: A multi-stakeholder spatial decision analysis (M-SSDA) for resilient landscapes. Sustainability, 9(7), 1113.

$\begin{array}{lll}\text { Convenzione di } & \text { Faro, }\end{array}$ 2005 https://www.coe.int/en/web/conventions/full-list//conventions/treaty/199 (last visit 20 december 2019).

Ciccozzi, E., Cerasoli, D., 2018. In cammino verso un mosaico per la rinascita della montagna abruzzese. Soggetti, settori produttivi e forme di ricostruzione socioeconomica. Scienze del territorio. Rivista di Studi Territorialisti, 6/2018, 131-137.

Daldanise, G., Gravagnuolo, A., Oppido, S., Ragozino, S. Cerreta, M., De Vita, G. E., 2019. Economie circolari per il patrimonio culturale: processi sinergici di riuso adattivo per la rigenerazione urbana, XXI National Conference SIU, CONFINI, MOVIMENTI, LUOGHI. Politiche e progetti per città e territori in transizione, Planum Publisher, Roma-Milano, 1348-1361

Douglas, J., 2006. Building adaptation. Routledge.

De Bonis, L., Giovagnoli, M., 2019. Territori fragili. Comunità, patrimonio, progetto. Scienze del territorio. Rivista di Studi Territorialisti, 7/2019.

Forgione, A., 2018. Scudi di frontiera. Dinamiche di conquista e di controllo normanno dell'Abruzzo aquilano. All'Insegna del Giglio, Sesto Fiorentino.

Giammarco, E., Lupinetti, M. Q., Ciglia, R., 1984. Navelli. Storia e arte. Editrice Italica, Pescara.

Gustafsson, C., 2019. Conservation 3.0 - cultural heritage as a driver for regional growth. SCIRES-IT-SCIentific RESearch and Information Technology, 9(1), 21-32.

Piano di Ricostruzione del Comune di Navelli (PdR), 2013. http://www.comunenavelli.gov.it/index.php?option=com_conte nt\&view=article\&id=309\&Itemid=158 (13 January 2020).
Porter, M. E., Kramer, M. R., 2011. The big idea: Creating shared value. Harvard Business Review, 89,1-2.

Redi, F., 1997. L'incastellamento nel territorio aquilano: primi dati per una ricerca archeologica. Archeologia Medievale, XXIV, 1997, 427-438.

USRC. Ufficio Speciale per la Ricostruzione dei Comuni del Cratere. I Piani di Ricostruzione (PdR). http://www.usrc.it/attivita/piani-di-ricostruzione/i-piani-diricostruzione (13 January 2020).

Struttura Tecnica di Missione (Stm), 2010. Considerazioni sulle finalità, gli obiettivi e $i$ profili economici dei Piani di Ricostruzione Ex Art. 14, Comma 5-Bis, Legge 77/2009 (http://www.commissarioperlaricostruzione.it/Informare/Normat ive-e-Documenti/Atti-e-documenti-della-Struttura-Tecnica-diMissione-STM/Parere-della-Commissione-Tecnico-Scientificasul-documento-della-STM-sui-Piani-di-Ricostruzione, last visit $13 / 01 / 2020)$.

Volpe, G., 2019. Patrimoni culturali e comunità colpite dai terremoti. Scienze del territorio. Rivista di Studi Territorialisti, 7/2019, 48-53.

Trizio, I., Continenza, R., Redi, F., 2017. Heritage Interpretation: a tool for conservation, protection and management of Environmental and Cultural Heritage. SCIRES-IT, SCIentific RESearch and Information Technology, Vol. 7, Issue 1, 39-44.

Zordan, L., Bellicoso, A., De Berardinis, P., Di Giovanni, G., Morganti, R., 2002. Le tradizioni del costruire della casa in pietra: materiali, tecniche, modelli e sperimentazioni. Università degli Studi dell'Aquila, Dipartimento di Architettura e Urbanistica. 